University of Nebraska - Lincoln

DigitalCommons@University of Nebraska - Lincoln

2010

\title{
Characterization of nanometer scale compositionally inhomogeneous AlGaN active regions on bulk AIN substrates
}

\author{
A. V. Sampath \\ US Army Research Laboratory, anand.sampath@us.army.mil \\ G. A. Garrett \\ US Army Research Laboratory \\ E. D. Readinger \\ US Army Research Laboratory \\ R. W. Enck \\ US Army Research Laboratory \\ H. Shen \\ US Army Research Laboratory \\ See next page for additional authors
}

Follow this and additional works at: https://digitalcommons.unl.edu/usarmyresearch

Part of the Operations Research, Systems Engineering and Industrial Engineering Commons

Sampath, A. V.; Garrett, G. A.; Readinger, E. D.; Enck, R. W.; Shen, H.; Wraback, M.; Grandusky, J. R.; and Schowalter, L. J., "Characterization of nanometer scale compositionally inhomogeneous AIGaN active regions on bulk AIN substrates" (2010). US Army Research. 150.

https://digitalcommons.unl.edu/usarmyresearch/150

This Article is brought to you for free and open access by the U.S. Department of Defense at DigitalCommons@University of Nebraska - Lincoln. It has been accepted for inclusion in US Army Research by an authorized administrator of DigitalCommons@University of Nebraska - Lincoln. 


\section{Authors}

A. V. Sampath, G. A. Garrett, E. D. Readinger, R. W. Enck, H. Shen, M. Wraback, J. R. Grandusky, and L. J. Schowalter 


\title{
Characterization of nanometer scale compositionally inhomogeneous AlGaN active regions on bulk AlN substrates
}

\author{
A.V. Sampath ${ }^{\text {a,* }}$, G.A. Garrett ${ }^{\text {a }}$, E.D. Readinger ${ }^{\mathrm{a}}$, R.W. Enck ${ }^{\mathrm{a}}$, H. Shen ${ }^{\mathrm{a}}$, M. Wraback ${ }^{\mathrm{a}}$, \\ J.R. Grandusky ${ }^{\text {b }}$, L.J. Schowalter ${ }^{\mathrm{b}}$ \\ ${ }^{a}$ US Army Research Laboratory, RDRL-SEE-M, 2800 Powder Mill Road, Adelphi, MD 20783, United States \\ ${ }^{\mathrm{b}}$ Crystal IS, Inc., 70 Cohoes Avenue, Green Island, NY 12183, United States
}

\section{A R T I C L E I N F O}

\section{Article history:}

Available online 25 June 2010

The review of this paper was arranged by Prof. A. Zaslavsky

\section{Keywords:}

Ultraviolet light emitting diodes

III-Nitrides

Defects

Radiative lifetime

\begin{abstract}
A B S T R A C T
The optical and structural properties of AlGaN active regions containing nanoscale compositional inhomogeneities $(\mathrm{NCI})$ grown on low dislocation density bulk AlN substrates are reported. These substrates are found to improve the internal quantum efficiency and structural quality of NCI-AlGaN active regions for high $\mathrm{Al}$ content alloys, as well as the interfaces of the $\mathrm{NCI}$ with the surrounding wider bandgap matrix, as manifested in the absence of any significant long decay component of the low temperature radiative lifetime, which is well characterized by a single exponential photoluminescence decay with a $330 \mathrm{ps}$ time constant. However, room temperature results indicate that non-radiative recombination associated with the high point defect density becomes a limiting factor in these films even at low dislocation densities for larger AlN mole fractions.
\end{abstract}

Published by Elsevier Ltd.

\section{Introduction}

Despite the recent progress in the development of III-Nitride semiconductor based deep ultraviolet light emitting diodes (DUVLEDs), commercially available devices emitting at wavelengths shorter than $280 \mathrm{~nm}$ still suffer from poor wall plug efficiencies on the order of $\sim 1 \%$ [1]. One factor limiting the performance of these devices is the presence of a large density of dislocations arising from the typical heteroepitaxial growth on c-plane sapphire substrates that are linked to a high non-radiative recombination rate. Previously, we have reported on the growth of AlGaN active regions containing self-assembled nanometer scale compositional inhomogeneities ( $\mathrm{NCl}-\mathrm{AlGaN}$ ) that demonstrate enhanced luminescence efficiency despite the presence of a large dislocation density [2]. This phenomenon is attributed to: (1) the high density of $\mathrm{NCI}$ regions that improves the probability of carriers recombining radiatively within them rather than non-radiatively at a structural defect and (2) the subsequent concentration of carriers within the narrower band gap $\mathrm{NCI}$ regions that suppresses non-radiative recombination and enhances radiative efficiency due to the reduced radiative lifetime at high carrier density [3,4]. Nevertheless, time-resolved photoluminescence (TRPL) studies show that the reduction of dislocation density in these materials further im-

\footnotetext{
* Corresponding author. Tel.: +1 3013940104; fax: +1 3013940310

E-mail address: anand.sampath@us.army.mil (A.V. Sampath).
}

proves LED active region performance, as characterized by an enhancement of the internal quantum efficiency (IQE) and the room temperature PL lifetime by $\sim 2 \times[5]$, a phenomenon that may be due to improved transport from the wider bandgap matrix to the $\mathrm{NCI}$ and concomitant higher carrier concentration therein. Bulk AlN has significant advantages over conventional $c$-plane sapphire as a substrate for III-Nitride based DUVLEDs, including a low dislocation density (etch pit density $<10^{4} \mathrm{~cm}^{-2}$ ), a reduced lattice mismatch, a high thermal conductivity, and a high transparency at wavelengths of interest. In this paper we report on the optical and structural properties of NCI-AlGaN films grown directly on bulk AlN substrates. In particular, we show a link between improved structural quality and longer non-radiative lifetime at room temperature, as well as suppression of deleterious long radiative lifetime components at low temperature associated with localization at interface fluctuations.

\section{Experimental method}

The samples grown on bulk AlN substrates consisted of a $600 \mathrm{~nm}$ thick, 70\% AlN mole fraction, NCI-AlGaN film deposited directly on the substrates by plasma assisted molecular beam epitaxy using conditions published elsewhere [6]. Prior to introduction into the reactor, the N-polar backsides of the substrates were sputter coated with a $\sim 2 \mu \mathrm{m}$ thick Ti film to improve heating uniformity, which was then capped with a protective $\mathrm{SiO}_{2}$ 
layer to prevent damage to the film during chemical preparation. Chemical preparation was performed immediately prior to loading the substrates into the reactor and consisted of solvent degreasing followed by etching in a $3: 1 \mathrm{HCl}: \mathrm{HNO}_{3}$ solution heated to $80^{\circ} \mathrm{C}$ for $\sim 10$ min and then removal of the $\mathrm{SiO}_{2}$ cap by dipping in BOE for $30 \mathrm{~s}$. Finally, the substrates were prepared in situ by annealing the substrate at the growth temperature of $900{ }^{\circ} \mathrm{C}$ while periodically covering the surface with Ga metal and then allowing the film to evaporate to remove surface oxides [7].

The optical properties of the samples were investigated by temperature dependent cw-photoluminescence using a $244 \mathrm{~nm}$ Coherent FReD Argon Ion Laser with a low output power of $\sim 0.5 \mathrm{~mW}$ so as to avoid effects associated with the saturation of defects or photo-bleaching that can result from the excitation of a large density of photogenerated carriers. The samples were cooled to $\sim 8 \mathrm{~K}$ using a cryostat and a closed-cycle He compressor. The photoluminescence lifetimes of the heterostructures were measured by timecorrelated single photon counting with $\sim 25$ ps resolution using a broadly tunable $(230-375 \mathrm{~nm})$ frequency doubled femtosecond optical parametric amplifier as the excitation source. The structural properties of the samples were investigated by X-ray diffraction using a Panalytical Xpert MRD diffractometer.

\section{Results}

X-ray diffraction (XRD) studies were employed to assess the improvement in the structural quality of the 70\% NCI-AlGaN films grown on bulk AlN substrates. Fig. 1 shows a reciprocal space map (RSM) of the NCI-AlGaN film along the asymmetric (1 0-14) direction that provides information on both the in-plane and out-ofplane lattice constants and therefore the strain state of the film. Specifically, the wurtzite lattice constants $a$ and $c$ are related to the reciprocal lattice points $Q_{x}$ and $Q_{y}$ by the relations $a=(2 \pi / Q x)^{a s t}\left(4 / 3\left(h^{2}+k^{2}+h k\right)\right)^{1 / 2}$ and $c=2 \pi^{*} l / Q_{y}[8,9]$. Therefore vertical lines in the RSM represent lines of constant $a$ lattice parameter and the degree of relaxation in the film may be calculated as $R=\left[a(L)-a_{0}(S)\right] /\left[a_{0}(L)-a_{0}(S)\right]$ where $a(L)$ and $a_{0}(L)$ are the measured and relaxed $a$ lattice constants of the alloy and $a_{0}(S)$ is the relaxed lattice constant of the substrate [8]. The narrow, intense peak in the top of the RSM map corresponds to the AIN substrate, while the broader peak in the bottom of the plot corresponds to the NCI-AlGaN layer deposited on top. The RSM reveals that the $600 \mathrm{~nm}$ thick $70 \% \mathrm{NCI}-\mathrm{AlGaN}$ film is highly strained to the AlN substrate with the degree of relaxation estimated to be $\sim 12.9 \%$. This result is consistent with those of Grandusky et al., who have reported on the ability to grow AlGaN films with AlN mole fractions $>60 \%$ pseudomorphically on bulk AlN substrates, with layer thicknesses between 0.5 and $1 \mu \mathrm{m}$ that are significantly greater than the critical thickness predicted by the Matthews-Blakeslee model [10]. As a result, these pseudomorphic AlGaN films are expected to replicate the structure of the bulk AlN substrate without the formation of dislocations. Therefore, the highly strained NCI-AlGaN film grown on bulk AlN is expected to contain a significantly lower dislocation density than similar fully relaxed films grown on $c$-plane sapphire or templates consisting of thin III-Nitride layers grown on $c$-plane sapphire. It should be noted that other groups have reported on strain relaxation in high AlN mole fraction films $(>60 \%)$ grown on sapphire or SiC substrates through the formation of dislocations $[11,12]$ in contrast to what we observe for growth of these films on bulk AlN. Understanding this result in terms of the differences in the strain relaxation mechanisms between the AlGaN/ bulk AlN system and the more commonly investigated AlGaN/AlN/c-plane sapphire system requires further investigation. The full width at half maximum (FWHM) of the XRD rocking curves along the $\left(\begin{array}{llll}0 & 0 & 0 & 2\end{array}\right)$ and $\left(\begin{array}{llll}1 & 0 & -1 & 4\end{array}\right)$ directions

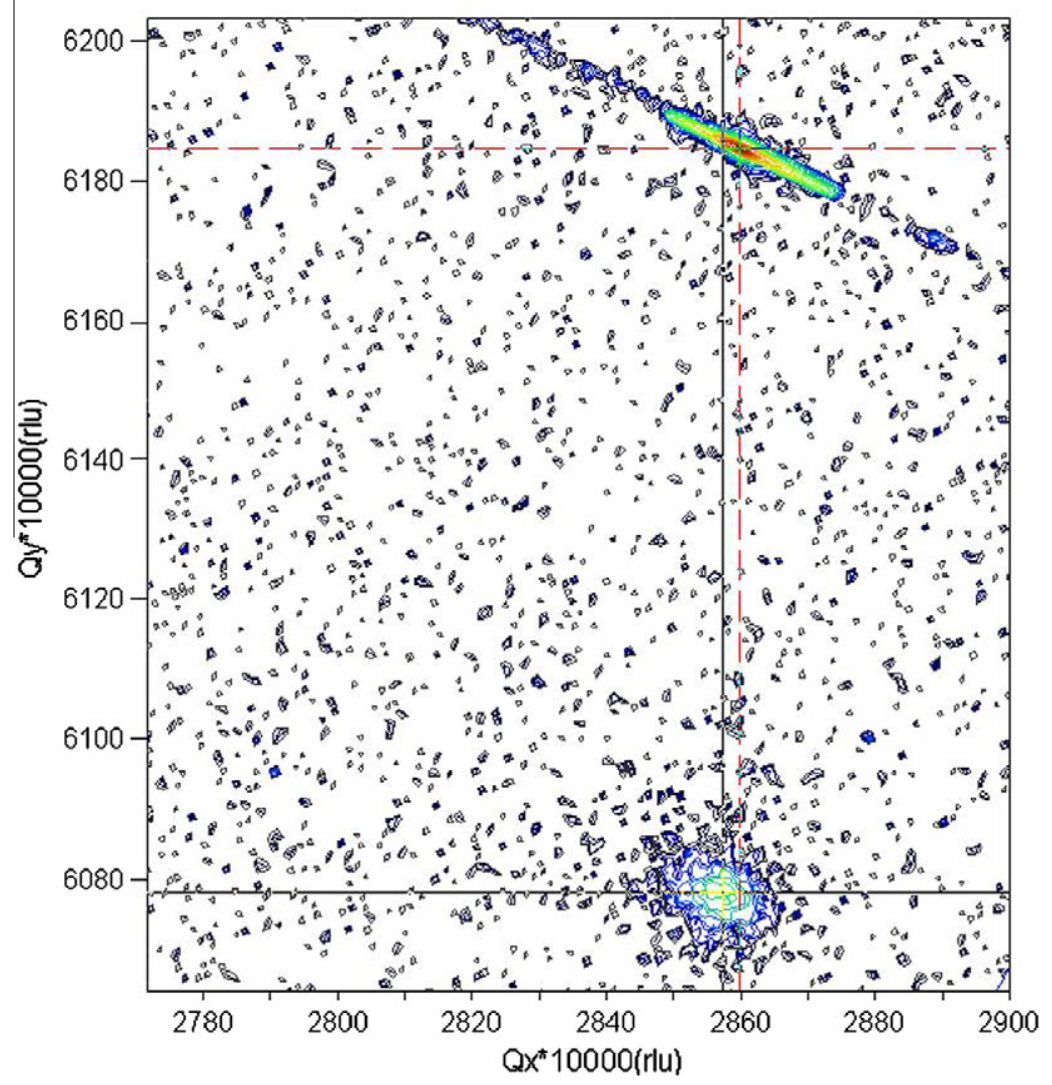

Fig. 1. (1 0-14) Reciprocal space map for NCI-AlGaN film on bulk AlN substrate. 
were observed to be $150^{\prime \prime}$ and $250^{\prime \prime}$, respectively, attesting to the epi-readiness of the surface of the bulk AlN substrate while representing a significant improvement over films grown directly on $c$ plane sapphire. However, these results are more comparable to fully relaxed AlGaN films investigated by Gradusky et al. rather than pseudomorphic AlGaN films that exhibited FWHM of the XRD rocking curve in the $\left(\begin{array}{lll}0 & 0 & 2\end{array}\right)$ and $(10-12)$ directions of $81^{\prime \prime}$ and $\sim 105^{\prime \prime}$, respectively [10]. While some of this broadening is likely related to the formation of dislocations at the heterointerface, it may also be partially attributed to the presence of the compositional inhomogeneities in the NCI-AlGaN films.

The room temperature and low temperature $(8 \mathrm{~K}) \mathrm{cw}$ photoluminescence (cw-PL) spectra for a typical $600 \mathrm{~nm}$ thick 70\% NCI-AlGaN film deposited on a bulk AlN substrate with room temperature emission at $\sim 272 \mathrm{~nm}$ are shown in Fig. 2. For comparison, the corresponding $\mathrm{cW}-\mathrm{PL}$ spectra for a $\mathrm{NCl}-\mathrm{AlGaN}$ single heterostructure (NCI-AlGaN-SH) consisting of a $80 \mathrm{~nm}$ thick NCI-AlGaN active region deposited upon a $2.3 \mu \mathrm{m}$ thick, Si doped AlGaN template grown by metalorganic chemical vapor deposition (MOCVD) and having $51 \%$ AlN by mole fraction are also shown. The PL emission spectrum of this structure peaks at $292 \mathrm{~nm}$. The internal quantum efficiency, as estimated by the ratio of the integrated cw-PL intensity measured at room temperature and $8 \mathrm{~K}$, increases from $26 \%$ for the $\mathrm{NCI}-\mathrm{AlGaN}-\mathrm{SH}$ to $34 \%$ for the film grown on the bulk AlN substrate. The room temperature time-resolved photoluminescence (TRPL) studies of both structures are shown in Fig. 3. The photogenerated carrier lifetime in the NCI-AlGaN film grown on the bulk AlN substrate is $220 \mathrm{ps}$, which is $\sim 25 \%$ longer than that in the $\mathrm{NCI}-$ AlGaN-SH, 175 ps.

Temperature dependent TRPL studies of the NCI-AlGaN film grown on bulk AlN and the NCI-AlGaN-SH are shown in Fig. 4. The photogenerated carrier lifetimes in both films decrease monotonically with increasing temperature, suggesting that nonradiative recombination limits their performance at room temperature. TRPL studies of the film on bulk AlN at low temperature, where non-radiative channels are frozen out, reveals a short radiative lifetime of $\sim 330 \mathrm{ps}$, which is faster than what we observe for the $\mathrm{NCI}-\mathrm{AlGaN}-\mathrm{SH}, \sim 444 \mathrm{ps}$, as well as faster than what we have previously observed for high quality multiple quantum well based active regions in commercially available LEDs on sapphire at similar emission wavelength [13].

\section{Discussion}

The enhancement in the integrated cw-PL intensity observed for the NCI-AlGaN film deposited on a bulk AlN substrate over that

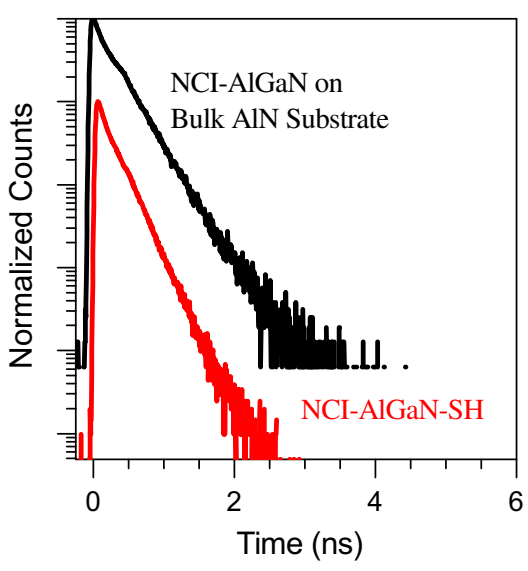

Fig. 3. Room temperature TRPL data for NCI-AlGaN film on bulk AlN substrate and NCI-AlGaN-SH on MOCVD template .

found for the NCI-AlGaN-SH, whose dislocation density is estimated to be $\sim 10^{8} \mathrm{~cm}^{-2}$ by transmission electron microscopy, is consistent with a reduction in the dislocation density in this film owing to a reduced lattice mismatch and a concomitant reduced strain relaxation that suppresses dislocation formation. The observed increase in IQE, from $26 \%$ for the NCI-AlGaN-SH to $34 \%$ for the film grown on the bulk AlN substrate, as well as the longer room temperature PL lifetime, which primarily tracks the nonradiative lifetime, for the film grown on the bulk AlN substrate provides further support for this interpretation (Table 1). As non-radiative recombination channels are frozen out at low temperature, the TRPL signature becomes more representative of the radiative lifetime. While the dominant component of this radiative lifetime is expected to become shorter with increasing $\mathrm{Al}$ content due to the larger exciton binding energy and concomitant oscillator strength, the extended decay in the TRPL observed at low temperature, which may be associated with a longer radiative lifetime related to carrier localization due to fluctuation of the $\mathrm{NCI} /$ matrix interfaces, is significantly suppressed in the films grown on the bulk AlN substrate compared to that of the NCI-AlGaN-SH or the high quality multiple quantum well samples on sapphire [13]. Taken together, these observations suggest improved structural quality related to the high quality bulk AlN substrate employed has a beneficial effect on non-radiative recombination rates at room temperature in the NCI-AlGaN films.

However, this enhancement in the room temperature optical properties of the NCI-AlGaN films on bulk AlN over those in the
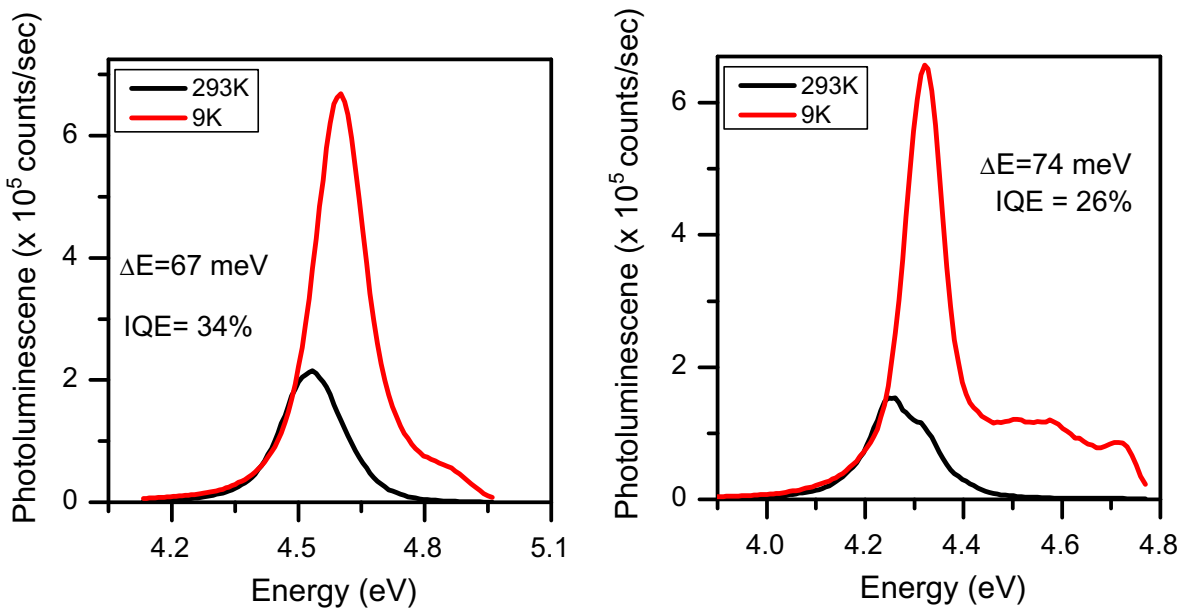

Fig. 2. Room temperature and low temperature cw-PL spectra for NCI-AlGaN film on bulk AlN substrate (left) and NCI-AlGaN-SH on MOCVD template (right). 

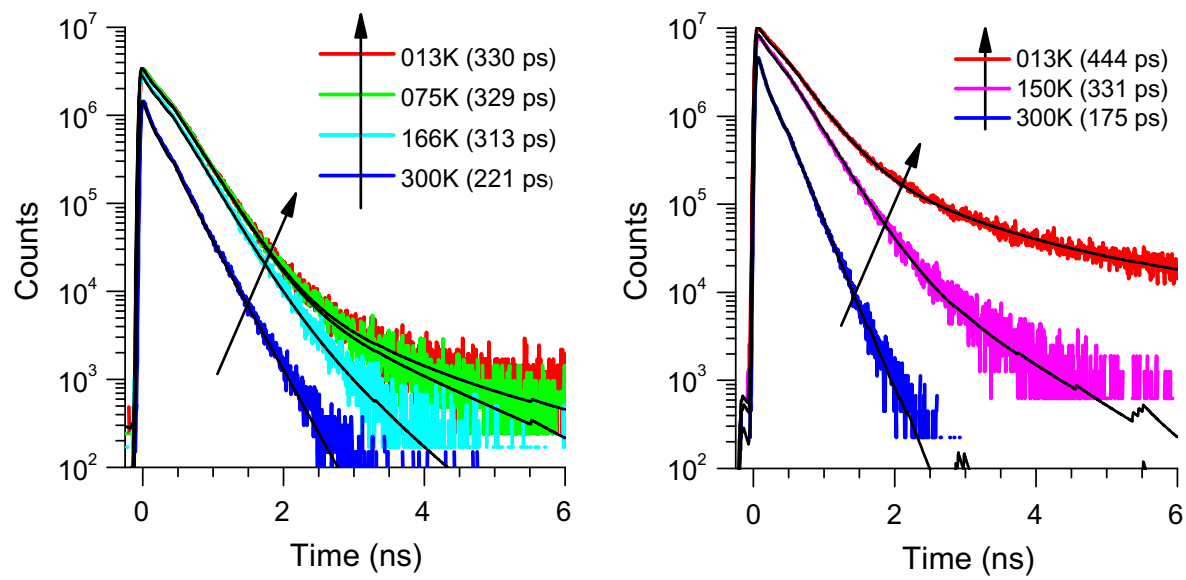

Fig. 4. Temperature dependent TRPL data for NCI-AlGaN film on bulk AIN substrate (left) and NCI-AlGaN-SH on MOCVD template (right).

Table 1

Optical and structural properties of investigated NCI-AlGaN films.

\begin{tabular}{|c|c|c|c|c|c|}
\hline NCI-AlGaN sample & Matrix AlN mole fraction (\%) & Dislocation density $\left(\mathrm{cm}^{-2}\right)$ & $\operatorname{IQE}(\%)$ & $\tau_{\mathrm{PL}} @ 293 \mathrm{~K}(\mathrm{ps})$ & $\tau_{\mathrm{PL}} @ 8 \mathrm{~K}(\mathrm{ps})$ \\
\hline On bulk AlN & 70 & $\ll 10^{8}$ & 34 & 220 & 330 \\
\hline $\mathrm{SH}$ & 51 & $\sim 10^{8}$ & 26 & 175 & 444 \\
\hline DH & 33 & $\sim 10^{10}$ & 30 & 530 & 439 \\
\hline
\end{tabular}

NCI-AlGaN-SH appears incommensurate with the dislocation density reduction due to the bulk AlN substrate. While the $\sim 25-30 \%$ improvement in the IQE and room temperature TRPL lifetime for the NCI-AlGaN film on bulk AlN as compared to the NCI-AlGaNSH may indicate only moderate structural improvement arising from the partial relaxation of the former, another explanation may be found through comparison with an NCI-AlGaN double heterostructure (DH) active region having only $33 \%$ AlN by mole fraction but a larger dislocation density due to the AlGaN template employed as the substrate (Table 1). This DH exhibits an IQE of $30 \%$ and a long PL lifetime of $\sim 530$ ps at room temperature that is primarily indicative of a long non-radiative lifetime due to localization of carriers in the $\mathrm{NCI}$ away from dislocations and saturation of the non-radiative centers within the $\mathrm{NCI}$ associated with the high carrier concentration in the NCI $[3,4]$. Further support for this interpretation is seen in the observed shortening of the photogenerated carrier lifetime at low temperature, where the radiative lifetime dominates. In contrast, the NCI-AlGaN film grown on the bulk AlN substrate exhibits a significantly shorter room temperature photogenerated carrier lifetime of $\sim 220$ ps despite having over two orders of magnitude lower dislocation density. While the IQE in these two films may be similar because of the large difference in radiative lifetime ( $\sim 650 \mathrm{ps}$ for the film on bulk AlN versus $\sim 2$ ns for the lower $\mathrm{Al}$ content $\mathrm{DH}$ at room temperature) attributed to the increase in the exciton binding energy with increasing AlN mole fraction, the decrease in PL lifetime with increasing temperature for the film on bulk AIN suggests that non-radiative recombination limits the PL lifetime, since the radiative lifetime is expected to increase with increasing temperature in the absence of significant quantum confinement in the NCI. The observed shortening of the PL lifetime with increasing AIN mole fraction is therefore more likely related to a significant concomitant increase in the density of point defects that compete effectively with the density of $\mathrm{NCI}$ regions in these films and partially mitigate the suppression of non-radiative recombination by the $\mathrm{NCI}$. These point defects may be associated with the increased $\mathrm{Al}$ in the films, which is known to getter impurities such as oxygen that are manifested as deep levels.

\section{Conclusions}

We have examined the structural and optical properties of AlGaN films containing compositional inhomogeneities on high quality, low defect density, bulk AlN substrates. These substrates are found to improve the internal quantum efficiency and structural quality of NCI-AlGaN active regions for high $\mathrm{Al}$ content alloys, as well as the interfaces of the NCI with the surrounding wider bandgap matrix, as manifested in the absence of any significant long decay component of the low temperature radiative lifetime, which is well characterized by a single exponential photoluminescence decay with a 330 ps time constant. The structural improvement of $\mathrm{NCI}-\mathrm{AlGaN}$ films grown on a bulk AlN substrate is attributed to reduced lattice mismatch and strain relaxation in the NCI-AlGaN films that inhibit the formation of dislocations. While improved structural quality related to the high quality bulk AlN substrate employed has a beneficial effect on non-radiative recombination rates at room temperature in the NCI-AlGaN films, the increasing density of point defects and impurities in these films with increasing AlN mole fraction are found to limit their performance as deep UV LED active regions, although less so than in comparable conventional structures due to the combination of low dislocation density and NCI.

\section{References}

[1] Khan A, Balakrishnan K, Kotona T. Nat Photonics 2008;2:77.

[2] Collins CJ, Sampath AV, Garrett GA, Sarney WL, Shen H, Wraback M, et al. Enhanced room temperature luminescence efficiency through carrier localization in AlxGa1-xN alloys. Appl Phys Lett 2005;86:031916-7.

[3] Wraback M, Garrett GA, Sampath AV, Shen H. Understanding ultraviolet emitter performance using intensity-dependent time-resolved photoluminescence. Int J High Speed Electron Syst 2007;17:179.

[4] Shen H, Sampath AV, Garrett GA, Wraback M. Mechanisms of enhanced luminescence in nanoscale compositionally inhomogeneous AlGaN. Electrochem Soc Trans 2006;3:181.

[5] Garrett GA, Sampath AV, Collins CJ, Readinger ED, Sarney WL, Shen H, et al. Phys Status Solidi C 2006;3:2125.

[6] Sampath AV, Garrett GA, Collins CJ, Sarney WL, Readinger ED, Newman PG, et al. J Electron Mater 2006;35:641.

[7] Smith L, King SW, Nemanich RJ, Davis RF. J Electron Mater 1996;25:805. 
[8] Pereira S, Correia MR, Pereira E, Donnel KP, Alves E, Sequeira AD, et al. Appl Phys Lett 2002;80:3913.

[9] Pereira S, Correia MR, Pereira E, Donnel KP, Alves E, Sequeira AD, et al. Appl Phys Lett 2002;81:3500.

[10] Grandusky J, Smart JA, Mendrick MC, Schowalter LJ, Chen KX, Schubert EF. J Cryst Growth 2009;311:2864.

[11] Follstaedt DM, Lee SR, Allerman AA, Floro JA. J Appl Phys 2009;105:083507-10.
[12] Cantu P, Wu F, Waltereit P, Keller S, Romanov AE, Mishra UK, et al. Appl Phys Lett 2003;83:674

[13] Garrett GA, Sampath AV, Shen H, Wraback M, Sun W, Shatalov M, et al. Evaluation of AlGaN-based deep ultraviolet emitter active regions by temperature dependent time-resolved photoluminescence. Phys Status Solidi C, accepted for publication. 